\title{
PENGARUH KECEPATAN PUTAR DEPOSISI TERHADAP STRUKTUR KRISTAL, KETEBALAN DAN MORFOLOGI LAPISAN TIPIS TIMBAL ZIRKONAT TITANAT (PZT) DENGAN METODE SPIN COATER
}

\section{EFFECTS OF ANGULAR VELOCITY ON CRYSTAL STRUCTURE, THICKNESS, AND MORPHOLOGY OF THIN FILM OF LEAD ZIRCONATE TITANATE (PZT) BY SPIN COATER METHOD}

\author{
Johnson Nune Naat ${ }^{1}$, Rachmat Triandi Tjahjanto ${ }^{1} \&$ Masruroh $^{2}$ \\ ${ }^{1}$ Jurusan Kimia, Fakutas Matematika dan Ilmu Pengetahuan Alam, \\ ${ }^{2}$ Jurusan Fisika, Fakutas Matematika dan Ilmu Pengetahuan Alam, \\ Universitas Brawijaya, Jalan Veteran Malang 65145, Jawa Timur, Indonesia \\ Alamat korespondensi: johnson_naat@yahoo.co.id dan ruroh@ub.ac.id
}

\begin{abstract}
Abstrak: Telah dilakukan penelitian pengaruh kecepatan putar terhadap struktur kristal, morfologi, ketebalan dan ukuran butir lapisan tipis PZT. Teknik pelapisan PZT dilakukan dengan spin coating dengan variasi kecepatan putar 2000, 3000 dan 4000 rpm. Kualitas kristal lapisan tipis PZT yang dihasilkan dikarakterisasi dengan XRD dan morfologi serta tampang lintang diobservasi dengan pencitraan SEM. Hasil karakterisasi menunjukkan puncak-puncak yang muncul adalah kristal perovskit dengan orientasi bidang kristal (001), (100), (101), (110), (200), (201) \& (210), dan (022). Semakin tinggi kecepatan putar makaketebalanlapisan PZT semakin tipis dan berpengaruh terhadap intensitas orientasi bidang kristal yang semakin menurun, serta morfologi permukaan semakin halus, rata dan homogen. Ketebalan pada kecepatan putar 2000, 3000 dan 4000 rpm berturut-turut 13,82; 12,66 dan 10,84 $\mu \mathrm{m}$ serta ukuran butir untuk masing-masing kecepatan putar sekitar 0,$6429 ; 0,6851$ dan $0,4237 \mu \mathrm{m}$. Hal ini dikarenakan semakin tinggi kecepatan putar mengakibatkan gaya sentrifugal semakin besar sehingga gel PZT terdistribusi secara merata dan homogen di atas permukaan substrat.
\end{abstract}

Kata kunci: PZT, kecepatan putar, struktur kristal, morfologi, ketebalan, ukuran butir

\begin{abstract}
The effect of the angular velocity on the crystal structure, morphology, thickness and grain size of PZT thin film has been successfully investigated. PZT film was coated based on the spin coating method with the angular velocity of 2000, 3000 and $4000 \mathrm{rpm}$. The crystalline quality of PZT thin film was characterized by $X R D$, while morphology and cross section were obserbved by SEM imaging. The results showed the perovskite crystal with the orientation of crystal planes on (001), (100), (101), (110), (200), (201), (210), and (022). The increase in the angular velocity indicated intensity of the crystal field orientation decreased, better morphology of fineness, flatness and homogeneity. Further more it was found the thickness of PZT thin film produced with the angular velocity of 2000,3000, and $4000 \mathrm{rpm}$ are 13.82, 12.66 and $10.84 \mu \mathrm{m}$, respectively with each grain size are 0.6429, 0.6851 and $0.423 \mu \mathrm{m}$. The higher of angular velocity result in the greater the centrifugal force, the homogenously and flat distributed of PZT gel on the surface.
\end{abstract}

Keywords: PZT, angular velocity, crystal structure, morphology, thickness, grain size.

\section{PENDAHULUAN}

Material keramik timbal zirkonat titanat $\left(\mathrm{PbZr}_{\mathrm{x}} \mathrm{Ti}_{1-\mathrm{x}}\right) \mathrm{O}_{3}$ sangat diminati oleh para peneliti karena mempunyai sifat ferroelektrik, dielektrik dan piezoelektrik yang baik (Song, 2012). Material PZT banyak digunakan dalam perangkat sensor, actuator, electromechanical (Mu, 2007), high frequency transducers (Mina, 2007), konversi energi mekanik menjadi energi listrik (Nguyen et al., 2013), micro electromechanical systems (MEMS) (Dauchy, 2007), sensor biomedis (Tseng et al., 2013). Material ini dibuat dalam bentuk kristal tunggal maupun bulk. Namun sepuluh tahun terakhir fabrikasinya dalam bentuk thin film (Umiati, 2001). Lapisan tipis (thin film) sangat dipengaruhi oleh ketebalan karena ketebalan akan mempengaruhi kualitas kristal dimana ketebalan yang berbeda akan menghasilkan kualitas kristal yang berbeda. Ketebalan lapisan tipis sangat ditentukan oleh kecepatan putar yang digunakan. Kecepatan putar merupakan salah satu faktor terpenting dalam proses spin coating. Kecepatan putar pada substrat berpengaruh terhadap sudut gaya sentrifugal yang mengenai cairan resin selain kecepatan dan turbulensiudara di atasnya. Secara lebih spesifik laju kecepatan putar yang tinggi menentukan morfologi, ukuran butir serta ketebalan lapisan yang terbentuk (Rustami, 2008) dan kecepatan putar dapat mempengaruhi tebal tipisnya lapisan (Purwanto, 2013). Spin coating dilakukan dengan cara deposisi larutan kimia di atas substrat, kemudian diputar dengan kecepatan tertentu. Kecepatan putar pada spin coating berpengaruh 
terhadap kualitas kristal dari material. Peningkatan kecepatan putar (rpm) spin coating umumnya mengakibatkan degradasi pada pembentukan lapisan tipis. Semakin cepat putaran akan diperoleh lapisan tipis yang semakin homogen dan tipis. Penelitian pada material polistirena dan polimetil metakrilat (PMMA) menunjukan bahwa semakin tinggi kecepatan putar ketebalan material semakin tipis. Hal ini terjadi karena semakin besar kecepatan putar maka semakin banyak larutan terpencar keluar substrat sehingga ketebalannya semakin menurun atau menjadi lebih tipis (Nuryani, 2009). Dengan spin coating dimungkinkan dapat diperoleh kualitas lapisan tipis yang semakin sempurna (Tilman, 2012). Ketika substrat pada kecepatan konstan dicirikan dengan penipisan pada lapisan secara perlahan sehingga didapatkan ketebalan lapisan yang homogen (Sueta, 2008). Dalam tulisan ini akan dibahas pengaruh kecepatan putar terhadap struktur kristal, morfologi ketebalan serta ukuran butir lapisan tipis timbal zirkonat titanat (PZT) yang dideposisi dengan teknik spin coating hasil sintesis metode solutiongelation (sol-gel).

\section{BAHAN DAN METODE}

Sintesis larutan prekursor PZT dilakukan di Laboratorium Kimia Anorganik Universitas Brawijaya, spin coating variasi kecepatan putar dilakukan di Laboratorium Fisika Material Universitas Brawijaya, karakterisasi XRD di Laboratorium Material dan Metalurgi ITS Surabaya sedangkan SEM-EDX di Laboratorium Biosains Universitas Brawijaya.

Alat-alat yang digunakan dalam penelitian ini yaitu: satu set komponen refluks, spin coater VTZ100, XRD (X-Ray diffraction), furnaces (tungku pemanas), Sonicator Branson 2510, oven Memmert UL30, neraca analitik, pipet volum $10 \mathrm{~mL}$, bola hisap, spatula, gelas arloji, corong kaca, porselen krusibel, mikropipet socorex 100-1000 $\mu \mathrm{L}$, hot plate stirrer digital cimarec dan magnetic stirrer.

Bahan-bahan yang digunakan dalam penelitian ini yaitu: timbal(II) asetat trihidrat $\left(\mathrm{Pb}\left(\mathrm{CH}_{3} \mathrm{COO}\right)_{2} .3 \mathrm{H}_{2} \mathrm{O}\right)$ dalam bentuk padatan / serbuk, zirkonium(IV) propoksida $\left(\mathrm{Zr}\left(\mathrm{OC}_{3} \mathrm{H}_{7}\right)_{4}\right)$ dalam bentuk larutan, titanium(IV) propoksida $\left(\mathrm{Ti}\left(\mathrm{OC}_{3} \mathrm{H}_{7}\right)_{4}\right)$ dalam bentuk larutan, PEG-400, asam asetat, metanol dan wafer silicon.

Sintesis prekursor menggunakan metode sol-gel dengan perbandingan mol Pb:Zr:Ti (1:0,5:0,5). Larutan prekursor (gel) PZT hasil sintesis selanjutnya dideposisi di atas substrat silikon ukuran $(1 \times 1 \mathrm{~cm})$. Kemudian dibuat 3 variasi kecepatan putar masingmasing 2000, 3000 dan $4000 \mathrm{rpm}$ dengan reactor spin coater dijalankan dan diset dengan kecepatan SPD1=500, SPD2=2000 rpm selama 60 detik (untuk kecepatan putar 3000 dan $4000 \mathrm{rpm}$ hanya berbeda pada SPD2). Selanjutnya dianiling dengan furnace pada temperatur $600^{\circ} \mathrm{C}$ selama 4 jam. Setelah dianiling film tipis PZT masing-masing di karakterisasi menggunakan difraksi sinar- $x$ (XRD) sudut $2 \theta$ dengan sudut putar $15^{\circ}-80^{\circ}$ dengan sumber sinar- $x$ dari logam tembaga $(\mathrm{Cu})$ dengan panjang gelombang $(\lambda) \mathrm{K}_{\alpha 1}$ sebesar 1,54056 ̊. Hasil XRD diperoleh difraktogram yang hasilnya dibandingkan dengan difraktogram PZT standar JCPDS. Morfologi, ukuran butir dan ketebalan diobservasi melalui pencitraan dengan SEM. Pengukuran ketebalan dilakukan dengan pengambilan 5 titik pada gambar tampang lintang (cross section) kemudian dirataratakan.

\section{HASIL DAN PEMBAHASAN}

Hasil XRD yang diperoleh berupa difraktogram lapisan tipis PZT terhadap variasi kecepatan putar 2000, 3000 dan $4000 \mathrm{rpm}$ yang disajikan pada Gambar 1. Gambar1 menunjukkan bahwa puncakpuncak yang muncul pada semua variasi kecepatan putar lapisan tipis PZT teridentifikasi dan terdapat kesesuaian dengan standar JCPDS (joint committee powder diffraction standar) No. 33-784.

Hasil XRD mengindikasikan bahwa lapisan tipis PZT memiliki struktur perovskit dengan orientasi bidang kristal (001), (100), (101), (110), (200), (201) \& (210), (022). Hasil ini menunjukkan bahwa lapisan tipis PZT memiliki struktur polikristalin. Intensitas puncak pada orientasi bidang kristal (101) lebih dominan dibandingkan dengan orientasi bidang kristal PZT yang lain. Hal ini sesuai dengan standar JCPDS bahwa intensitas orientasi bidang kristal (101) lebih tinggi dari orientasi bidang kristal lainnya karena struktur dasar substrat yang digunakan silikon berbentuk kubus yang merupakan ciri khas dari struktur kristal perovskit. Hasil difraktogram juga menunjukkan adanya puncak zirkonium oksida $\left(\mathrm{ZrO}_{2}\right)$ pada $2 \theta=35^{\circ}$ dan $60^{\circ}$ berdasarkan JCPDS nomor 14-534 pada semua variasi kecepatan putar yang menunjukkan adanya zirkonium yang tidak terlibat dalam pembentukan struktur perovskit. Hal ini disebabkan karena adanya interaksi zirkonium dengan oksigen baik pada proses pemekatan gel PZT maupun aniling.

Dari hasil XRD difraktogram pada Gambar 1 menunjukkan bahwa semua intensitas orientasi bidang kristal PZT semakin menurun seiring meningkatnya kecepatan putar. Lebih jelasnya dapat dilihat pada Tabel 1 intensitas beberapa orientasi bidang kristal lapisan tipis PZT. Semakin tinggi kecepatan putar, gaya sentrifugal yang dihasilkan semakin besar sehingga semakin banyak gel PZT terpencar keluar substrat akibatnya ketebalan lapisan tipis semakin menurun. Ketebalan lapisan tipis berkorelasi linear dengan intensitas stuktur kristal.

Menurunnya ketebalan berarti jumlah atom-atom penyusun PZT makin berkurang, sehingga probabilitas pembentukan PZT berkurang yang mempengaruhi intensitas hasil XRD. Hal ini didukung data ketebalan lapisan tipis PZT citra SEM tampang lintang (cross section) yang menunjukkan ketebalan semakin menurun dengan meningkatnya 
kecepatan putar. Data nilai ketebalan dapat dilihat pada Tabel 2. Peningkatan kecepatan putar spin coating umumnya mengakibatkan degradasi pada pembentukan lapisan tipis.

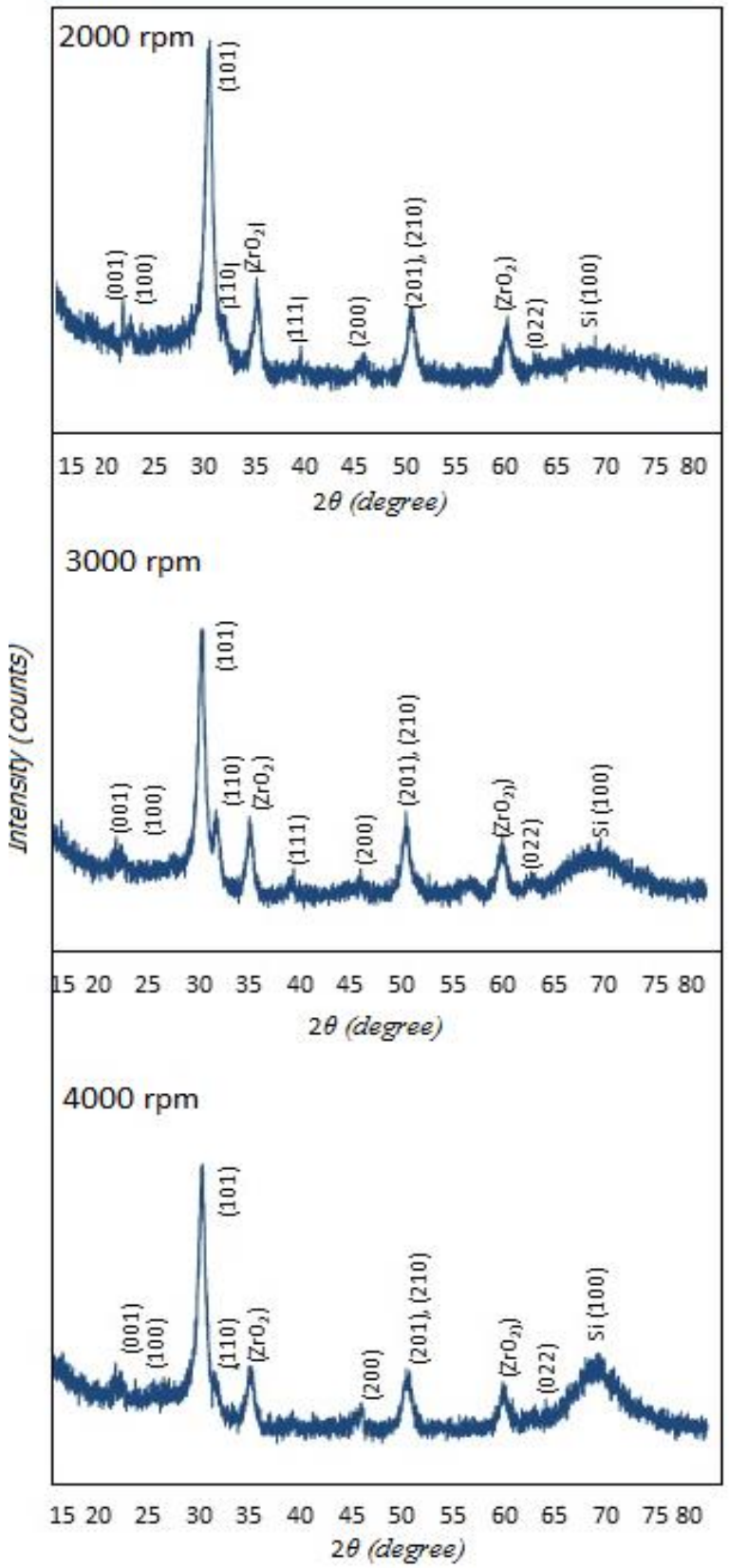

Gambar 1. Difraktogram lapisan tipis PZT variasi kecepatan putar 2000, 3000 dan $4000 \mathrm{rpm}$.

Hasil citra SEM morfologi lapisan tipis PZT pengaruh kecepatan putar 2000, 3000 dan $4000 \mathrm{rpm}$ dengan perbesaran 12000x disajikan pada Gambar 2. Hasil foto SEM menunjukkan ada pengaruh kecepatan putar terhadap morfologi lapisan tipis PZT. Secara ringkas dapat dilihat pada Tabel 2. Kecepatan putar berhubungan dengan kekasaran lapisan tipis yang terbentuk di atas substrat. Kecepatan putar 2000 dan $3000 \mathrm{rpm}$ nampak morfologi permukaan yang masih kasar dan tidak rata. Hal ini diduga karena gel
PZT hasil sintesis sangat kental sehingga gaya sentrifugal yang dihasilkan dengan kecepatan putar 2000 dan $3000 \mathrm{rpm}$ tidak mampu mendistribusikan gel PZT secara merata di atas permukaan substrat.
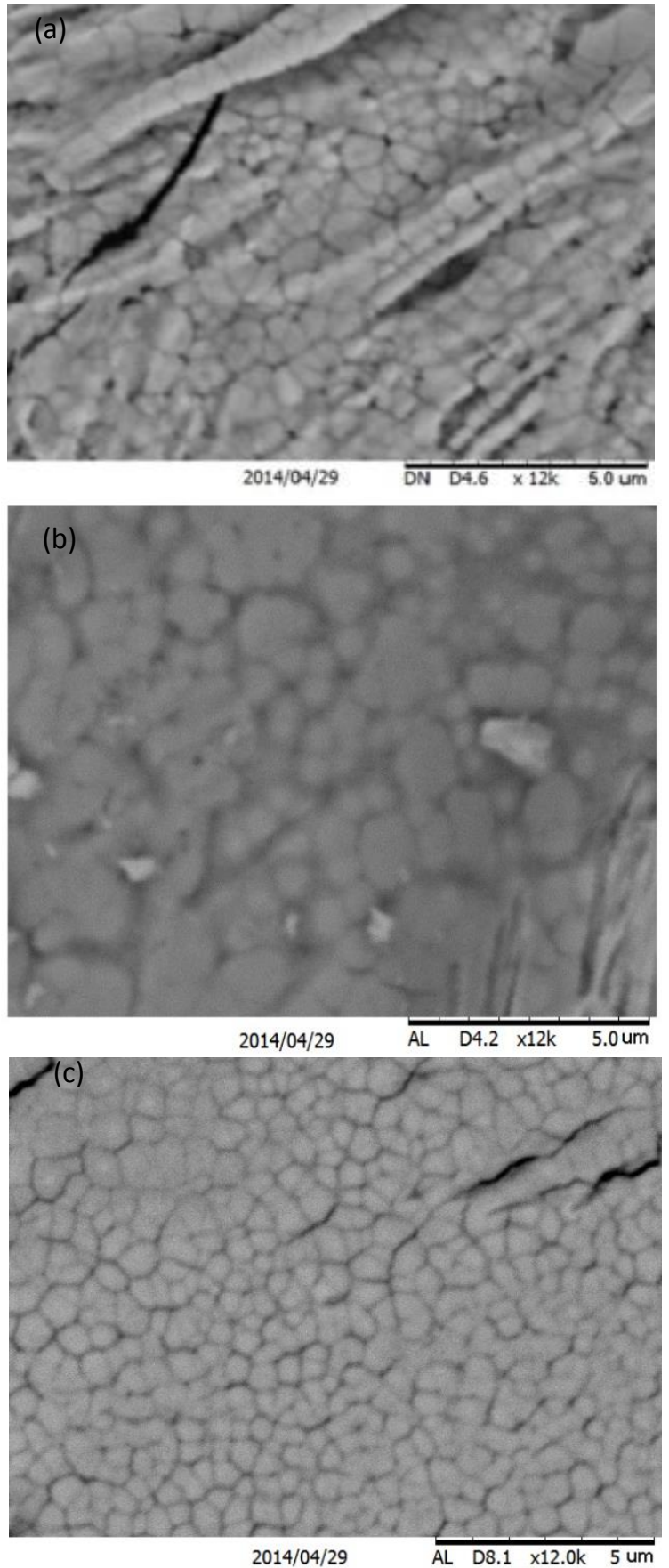

Gambar 2. Morfologi lapisan tipis PZT kecepatan putar perbesaran 12000x:(a). $2000 \mathrm{rpm}$ (b). $3000 \mathrm{rpm}$, (c). $4000 \mathrm{rpm}$.

Penelitian yang dilakukan oleh Yosefina, dkk (2007) pada material BST melaporkan bahwa jika kecepatan putar yang digunakan sangat kecil maka akan menghasilkan permukaan yang kasar. Pada Gambar 2(c) kecepatan putar 4000 rpm, gaya sentrifugal yang dihasilkan mampu mendistribusikan 
gel PZT di atas permukaan substrat. Sehingga diperoleh morfologi permukaan yang lebih halus, rata dan homogen atau kualitas morfologi permukaan yang semakin sempurna, seperti yang terlihat pada Gambar 2c dan Tabel 2.

Morfologi lapisan tipis variasi kecepatan putar terlihat adanya retakan (crack). Hal ini disebabkan karena larutan hasil sintesis berbentuk gel kental (pekat), gel yang kurang merata di atas permukaan substrat dan laju kenaikan dan penurunan suhu yang tidak sama. Penurunan suhu yang tidak sama sampai temperatur kamar menyebabkan ketidakstabilan atom-atom dalam menerima panas. Hasil penelitian pada material BST (barium bismuth tantalum) juga membuktikan bahwa prekursor hasil sintesis dengan kekentalan yang tinggi akan menyebabkan retakan pada permukaan lapisan tipis (Costa, 2003). Pada Gambar 2 di atas dapat diobservasi ukuran butir lapisan tipis PZT. Variasi kecepatan putar spin coating menyebabkan variasi pada ukuran butir. Semakin besar kecepatan putar, ukuran butir cenderung menurun dan semakin homogen. Hal ini disebabkan oleh gaya sentrifugal yang dihasilkan semakin besar ketika kecepatan putar meningkat. Gaya sentrifugal yang besar, cenderung menarik massa gel keluar sehingga massa gel terdistribusi secara merata.

Tabel 1. Intensitas beberapa orientasi bidang kristal PZT variasi kecepatan putar

\begin{tabular}{cccc}
\hline \multirow{3}{*}{ Bidang $h k l$} & \multicolumn{3}{c}{ Intensitas PZT (counts) } \\
\cline { 2 - 4 } & 2000 & 3000 & 4000 \\
\cline { 2 - 4 } & 962 & 829 & 777 \\
$(101)$ & 325 & 287 & 251 \\
$(001)$ & 289 & 276 & 246 \\
$(100)$ & 361 & 307 & 292 \\
\hline
\end{tabular}

Tabel 2. Morfologi, ketebalan dan ukuran butir lapisan tipis PZT variasi kecepatan putar

\begin{tabular}{ccccccc}
\hline $\begin{array}{c}\text { Kecepatan } \\
\text { putar }(\mathrm{rpm})\end{array}$ & $\begin{array}{c}\text { Ketebalan } \\
(\mu \mathrm{m})\end{array}$ & $\begin{array}{c}\text { Ukuran butir } \\
(\mu \mathrm{m})\end{array}$ & Batas Butir & Kehalusan & Kehomogenan & $\begin{array}{c}\text { Retakan } \\
(\text { crack })\end{array}$ \\
\hline 2000 & 13,82 & 0,6429 & Ada & tidak halus & tidak homogen & ada \\
3000 & 12,66 & 0,6851 & Ada & tidak halus & tidak homogen & $\begin{array}{c}\text { ada } \\
\text { homogen }\end{array}$ \\
4000 & 10,84 & 0,5237 & Ada & Halus & ada \\
\hline
\end{tabular}

Dengan demikian kecepatan putar sangat berpengaruh terhadap struktur kristal, ketebalan, ukuran butir dan morfologi lapisan tipis PZT. Semakin tinggi kecepatan putar, intensitas struktur kristal, ketebalan dan ukuran butir relatif semakin menurun dan morfologi yang semakin halus, rata dan homogen.

\section{KESIMPULAN}

Hasil analisis dengan XRD menunjukkan pada kecepatan putar 2000, 3000 dan 4000 rpm muncul puncak kristal perovskit dengan orientasi bidang kristal (001), (100), (101), (110), (200), (201) dan (210), (022). Hasil SEM menunjukkan morfologi permukaan semakin halus, rata dan homogen dengan meningkatnya kecepatan putar. Ketebalan lapisan tipis pada kecepatan putar 2000, 3000 dan $4000 \mathrm{rpm}$ berturut-turut 13,$82 ; 12,66$ dan $10,84 \mu \mathrm{m}$ serta ukuran butir 0,$6429 ; 0,6851$ dan $0,4237 \mu \mathrm{m}$.

\section{DAFTAR PUSTAKA}

Costa, G., Simões, A.Z., Gisele, G. \& Zaghette, M.A. (2003). Effect of viscosity and temperature on the microstructure of BBT thin films. Journal of Material Research. 6(3): 347-351.

Dauchy, F., \& Dorey, R.A. (2007). Patterned Crack Free PZT Thick Films for Micro
Electromechanical System Applications. University of Cranfield.

Mina, G. I. (2007). High Frequency Transducers From PZT Films. Pennsylvania State University.

$\mathrm{Mu}$, G. (2007). Synthesis of PZT nanocrystalline powder by a modified sol-gel process using water as primary solvent source. Journal of Materials Processing Technology. 128: 382-386.

Nguyen, D., Matthijn, D., Hung, N. V. \& Guus, R. (2013). Film thickness and composition dependence of epitaxial thin-film PZTbasedmass-sensors. Journal of sensors and actuators A : Physical. 199: 98- 105.

Nuryani, I. (2009). Studi fabrikasi Lapisan tipis tiga lapis bahan polystyrene dan polymethyl methacrylate (PMMA) dengan teknik spin coating. ITS Surabaya.

Purwanto, Romli. \& Prajitno G. (2013). Variasi kecepatan dan waktu pemutaran spin coating dalam pelapisan $\mathrm{TiO}_{2}$ untuk pembuatan dan karakterisasi prototipe DSSC dengan ekstraksi kulit manggis (garcinia mangostana) sebagai dye sensitizer, ITS Surabaya.

Rustami, E. (2008). Sistem kontrol kecepatan putar spin coating berbasis mikrokontroler, IPB Bogor.

Sueta, N. (2008). Pembuatan dan karakterisasi lapisan $\mathrm{Ba}_{0,5} \mathrm{Sr}_{0,5} \mathrm{TiO}_{3}$ (BST) yang didoping 
dengan magnesium dengan metode chemical solution deposition (CSD), Universitas Indonesia.

Song, H. W. (2012). The effect of deposition temperature of $\mathrm{Pb}(\mathrm{Zr}, \mathrm{Ti}) \mathrm{O}_{3}(\mathrm{PZT})$ thin films with thicknesses of around $100 \mathrm{~nm}$ on the piezoelectric response for nano storage applications. World Journal of Condensed Matter Physics, 2: 51-56.

Tilman, M. (2012). Effect of constrained sintering on the piezoelectric properties of PZT thick films, Cranfield University.

Tseng, H.J., Wei, C.T. \& Wen, J. W. (2013). Flexible PZT thin film tactile sensor for biomedical monitoring. Journal of sensor. 13: 5478-5492.

Umiati, N.A.K. (2001). Efek Annealing pada Penumbuhan Film Tipis Ferroelektrik $\mathrm{PbZr}_{0,625} \mathrm{Ti}_{0,375} \mathrm{O}_{3}$ (PZT). Jurnal Kontribusi Fisika Indonesia. 12(4): 94-98.

Yofentina I., Viska I.V., Hikam, M. \& Soegijono, B. (2007). Batasan kecepatan putar spin coater pada penumbuhan lapisan tipis barium strontium titanat 0,5 M. Indonesian Journal of Materials Science. 103-106. 